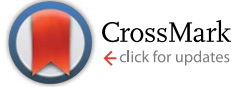

Cite this: J. Mater. Chem. A, 2014, 2 , 15575

Received 27th June 2014

Accepted 6th August 2014

DOI: $10.1039 / c 4 t a 03278 k$

www.rsc.org/MaterialsA

\title{
Hierarchical amorphous nanofibers for transparent inherently super-hydrophilic coatings $\dagger$
}

\author{
William S. Y. Wong, ${ }^{a}$ Noushin Nasiri, ${ }^{a}$ Alexandra L. Rodriguez, ${ }^{b}$ David R. Nisbet ${ }^{b}$ \\ and Antonio Tricoli*a
}

\begin{abstract}
Ultra-high specific surface area, hierarchical $\mathrm{TiO}_{2}$ nanofibers were synthesized by electrospinning and directly self-assembled into highly porous films for application as transparent super-hydrophilic coatings. The evolution of the coating key structural properties such as fiber morphology and composition was mapped from the as-prepared sol-gel up to a calcination temperature of $500{ }^{\circ} \mathrm{C}$. Main fiber restructuring processes such as formation of amorphous $\mathrm{Ti}-\mathrm{O}$ bonds, crystallization, polymer decomposition and the organic removal were correlated to the resulting optical and wetting performance. Conditions for low-temperature synthesis of hierarchical coatings made of amorphous, mesoporous $\mathrm{TiO}_{2}$ nanofibers with very high specific surface area were determined. The wetting properties of these amorphous and crystalline $\mathrm{TiO}_{2}$ nanofiber films were investigated with respect to the achievement of inherently super-hydrophilic surfaces not requiring UV-activation. The surface stability of these amorphous $\mathrm{TiO}_{2}$ nanofibers was assessed against current state-of-the-art crystalline superhydrophilic $\mathrm{TiO}_{2}$ preserving excellent anti-fogging performance upon an extended period of time (72 h) in darkness.
\end{abstract}

\section{Introduction}

Since their first synthetic fabrication over a decade ago, superhydrophilic surfaces have attracted substantial scientific interest ${ }^{1}$ as they achieve a water sheeting effect within a very short timeframe ( $c a .0 .5 \mathrm{~s}) .^{2-4}$ The resulting implications with respect to the condensation, evaporation and transport of (nonand atmospheric) water have led to their consideration for numerous commercial applications, including anti-fogging, ${ }^{5,6}$ self-cleaning, ${ }^{7}$ anti-fouling, ${ }^{8}$ bio-implants, ${ }^{9}$ micro-lenses, ${ }^{10}$ labon-a-chip, ${ }^{11}$ microfluidics, ${ }^{6,12}$ fog-harvesting, ${ }^{13}$ and heat transfer enhancement. $^{14}$

Several lab-scale methods have been successfully established for the synthesis of super-hydrophilic coatings including plasma, electrochemical treatment, ${ }^{6}$ reactive ion etching, ${ }^{5}$ micropatterning ${ }^{8,13}$ and flame spray pyrolysis. ${ }^{15}$ However, their wetting mechanism is still intensely debated. The complete spreading of a water droplet on a surface (perfect wetting) is expected on materials having high water affinity such as that generated by high surface concentrations of hydroxyl $(-\mathrm{OH})$ groups. ${ }^{16,17}$ As a result, ideal super-hydrophilicity leads to a

${ }^{a}$ Nanotechnology Research Laboratory, Research School of Engineering, Australian National University, Canberra 0200, Australia. E-mail: antonio.tricoli@anu.edu.au ${ }^{b}$ Laboratory of Advanced Biomaterials, Research School of Engineering, Australian National University, Canberra 0200, Australia

$\uparrow$ Electronic supplementary information (ESI) available: TGA, DTG. See DOI: $10.1039 / \mathrm{c} 4 \mathrm{ta} 03278 \mathrm{k}$ contact angle $(\theta)$ nearing 0 and is achieved, according to Young's equation, for:

$$
\gamma_{\mathrm{s}} \geq \gamma_{1}+\gamma_{\mathrm{sl}}
$$

where $\gamma_{s}$ is the solid surface free energy, $\gamma_{1}$ is the liquid surface free energy (surface tension), $\gamma_{\mathrm{sl}}$ is the solid/liquid interfacial free energy. Given that this is the case for many materials (with the notable exception of organic polymers) ${ }^{18}$ super-hydrophilicity should be fairly common. However, spontaneous superhydrophilic surfaces are rarely observed. This is usually attributed to the presence of a layer of volatile organics/gas molecules rapidly adsorbing onto the surfaces of these materials. ${ }^{19,20}$ To overcome these limitations, morphological modifications such as surface texturing have been utilized to enhance chemically-driven water spreading over that of perfectly flat surfaces. ${ }^{21}$

Titanium dioxide $\left(\mathrm{TiO}_{2}\right)$ is a widely utilized photocatalytic and ultraviolet (UV)-augmented material with high $\mathrm{H}_{2} \mathrm{O}$ affinity that has been investigated for its photoactive, ${ }^{22,23}$ self-cleaning, ${ }^{23,24}$ optical ${ }^{25}$ and chemical sensing ${ }^{26}$ properties. Traditionally, the super-hydrophilicity of $\mathrm{TiO}_{2}$ films has been found to correlate closely to UV exposure ${ }^{1,27,28}$ For instance, UV-induced super-hydrophilicity has been investigated using thin sol-gelmade polycrystalline $\mathrm{TiO}_{2}$ films annealed at $500{ }^{\circ} \mathrm{C}$. These films required surface activation, becoming super-hydrophilic when exposed to UV irradiation and hydrophobic when kept in the dark. ${ }^{1}$ Similar behaviors have been observed for amorphous 
$\mathrm{TiO}_{2}$ films. ${ }^{27,28}$ This is a main limitation of $\mathrm{TiO}_{2}$ that is known to lose super-hydrophilicity within a few minutes ${ }^{20}$ to one day ${ }^{19,29,30}$ upon last exposure to UV-light.

Doping of sol-gel-made $\mathrm{TiO}_{2}{ }^{3,29}$ and mesoporous surface enhancement ${ }^{31}$ have been used to promote UV-independent super-hydrophilicity. Highly rough $\mathrm{TiO}_{2}$ films deposited by metal-organic vapor deposition were found to prevent the oxidation of $\mathrm{Ti}^{3+}$ during periods of darkness and were able to maintain super-hydrophilicity for extended periods (2-3 days) post UV-activation. ${ }^{32}$ Amongst other $\mathrm{TiO}_{2}$ synthesis methods, electrospinning is a scalable, atmospheric process that offers several structural advantages. Electrospun coatings are continuously self-assembled during fiber synthesis, leading to a very porous multi-layer structure having considerably higher flexibility than PVD/CVD-made films ${ }^{32,33}$ and mechanical stability than aerosol-deposited nanoparticle layers. ${ }^{\mathbf{1 5 , 3 4}}$ Electrospinning of polyvinyl pyrrolidone-titanium(Iv) isopropoxide (PVP-TTIP) sol-gel mixtures has led to some of the thinnest $\mathrm{TiO}_{2}$ fibers so far reported..$^{35,36}$ However, the optimization of electrospun $\mathrm{TiO}_{2}$ nanofiber composition and morphology for fabrication of UVindependent, super-hydrophilic coatings has not yet been reported.

Here, the synthesis of amorphous $\mathrm{TiO}_{2}$ nanofibers for the fabrication of transparent and inherently super-hydrophilic coatings has been investigated. The evolution of the key fiber structural properties was mapped as a function of calcination temperature in terms of morphology, bulk and surface compositions leading to a well-characterized set of amorphous and crystalline $\mathrm{TiO}_{2}$ nanofiber coatings. Structural-functional correlations of these materials have been established with respect to their wetting and optical properties. A novel hierarchical amorphous $\mathrm{TiO}_{2}$ nanofiber morphology with excellent anti-fogging performance was identified and compared to stateof-the-art anatase crystalline coatings.

\section{Experimental}

\section{Materials and fabrication}

Nanofibers were obtained by electrospinning of an ethanolbased sol-gel (0.06 $\mathrm{g} \mathrm{mL}^{-1} \mathrm{PVP}$ and $\left.0.0936 \mathrm{~g} \mathrm{~mL}^{-1} \mathrm{Ti}(\mathrm{OiPr})_{4}\right)$, with acetic acid as a hydrolysis promoter. ${ }^{35}$ A PVP solution was first prepared by dissolving $0.6 \mathrm{~g}$ of PVP (Sigma Aldrich, $M_{\mathrm{w}}=$ $1300000)$ in $5 \mathrm{~mL}$ of ethanol (Sigma Aldrich, 200 proof). A solgel solution was then prepared using $2 \mathrm{~mL}$ of ethanol, $2 \mathrm{~mL}$ of acetic acid (glacial, Chem-Supply) and $1 \mathrm{~mL}$ of Ti(OiPr) ${ }_{4}$ (Sigma Aldrich). Solutions were stirred for 10 minutes before introducing the sol-gel mixture into the PVP solution. A clear yellowish solution was obtained, which was electrospun after 1 hour of mixing. An applied voltage of $25 \mathrm{kV}$ was used with a working distance and flow rate of $20 \mathrm{~cm}$ and $0.8 \mathrm{~mL} \mathrm{~h}^{-1}$, respectively, providing homogenous coverage of nanofibers on the glass substrates. Surface coverage was confirmed by optical microscopy. A deposition time of 1 minute was used to obtain clear, transparent coatings. Once collected on glass slides, the coatings were stored at room temperature for 5-6 hours to allow for the completion of hydrolysis. Samples were then calcined for 1 hour $\left(3{ }^{\circ} \mathrm{C} \mathrm{min}^{-1}\right)$ between $100{ }^{\circ} \mathrm{C}$ and $500{ }^{\circ} \mathrm{C}\left(T_{\mathrm{s}}\right)$.

\section{Characterization}

Calcined coatings were then kept in the dark at room temperature for 3 days before proceeding to the wetting studies. The dynamic water contact angle (CA) was measured by placing a drop of deionized water $(5-6 \mu \mathrm{L})$ on the sample surface using a KSV CAM200 contact angle goniometer (Finland) with a heliopan ES43 camera (Japan). The CA was computed by a commercially available (CAM2008) program. Samples were analyzed using a Zeiss UltraPlus analytical scanning electron microscope (FESEM) at $3 \mathrm{kV}$ and a Hitachi H7100FA $125 \mathrm{kV}$ transmission electron microscope (TEM). Prior to examination, SEM specimens were platinum sputtercoated for $2 \mathrm{~min}$ at $20 \mathrm{~mA}$. Average fiber diameters $\left(d_{\mathrm{EM}}\right)$ were determined by counting with ImageJ 20 fibers in each SEM image. TEM specimens were suspended and dispersed in ethanol (Sigma Aldrich, 200 proof) before they were deposited on 200-mesh nickel-copper grids (Formvar) and dried at room temperature. UV-vis analysis was conducted using a microplate reader (Tecan 200 PRO, Switzerland) from 300-800 nm with 10 scans per cycle. The crystal phases, size $\left(d_{\mathrm{XRD}}\right)$ and surface compositions were analyzed by X-ray diffraction (XRD, D2 Phaser, Bruker, U.S.A) and Fourier transform infrared spectroscopy (FTIR-ATR, Bruker-Alpha, U.S.A). Amorphous samples in $\mathrm{XRD}\left(<400{ }^{\circ} \mathrm{C}\right)$ were normalized using the first crystalline anatase 101 peak achieved at $400{ }^{\circ} \mathrm{C}$. The Brunauer-EmmettTeller specific surface area (BET, SSA), pore volume and distribution of the as-prepared coatings were measured by $\mathrm{N}_{2}$ adsorption using a porosity analyzer (Micromeritics, TriStar II, U.S.A). All samples were degassed at $300{ }^{\circ} \mathrm{C}$ for 5 hours prior to analysis. Evaluation of the antifogging performance was conducted on selected calcined coatings $\left(300{ }^{\circ} \mathrm{C}, 350{ }^{\circ} \mathrm{C}, 500{ }^{\circ} \mathrm{C}\right)$ by exposure to a vapor stream $40 \mathrm{~cm}$ above boiling water for 5$10 \mathrm{~s}$, as previously reported. ${ }^{15}$ Thermogravimetric (TGA) and differential thermogravimetry (DTG) analysis were conducted from $100-800{ }^{\circ} \mathrm{C}\left(3{ }^{\circ} \mathrm{C} \mathrm{min}^{-1} \mathrm{ramp}\right)$ and isothermally at $350{ }^{\circ} \mathrm{C}$ for $1 \mathrm{~h}$ under atmospheric conditions (Perkin Elmer, STA 8000, U.S.A).

\section{Results and discussion}

\section{Synthesis and characterization of hierarchical nanofibers}

The as-prepared nanofibers had a flexible structure with notable formation of hoop and spiral shapes (Fig. 1a) upon evaporation of the solvent utilized for TEM preparation. Their appearance was flaky, revealing a porous morphology and a very rough surface. Upon low temperature $\left(T_{\mathrm{s}}=250-350{ }^{\circ} \mathrm{C}\right)$ calcination, the fibers' diameters shrunk rapidly (Fig. 1b and c) leading to increased rigidity and relatively smooth surface morphologies. Increasing the calcination temperature to $500{ }^{\circ} \mathrm{C}$ had minimal impact on the fiber size but increased surface roughness, resulting in a granular appearance with a grain size of $c a .20 \mathrm{~nm}$ (Fig. 1d, inset). This is in line with previous reports on hightemperature calcined $\mathrm{TiO}_{2}$ fibers, ${ }^{25}$ attributing this morphology to crystal nucleation.

The SEM analysis (Fig. 2) of the coatings supported these observations with the average fiber count diameter decreasing 

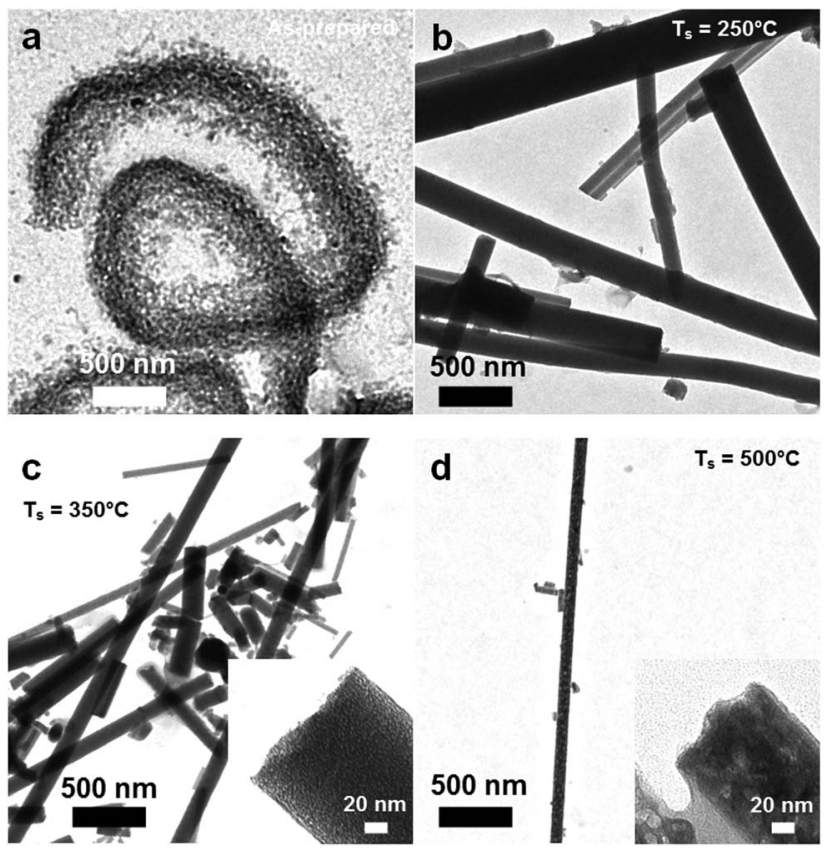

Fig. 1 TEM images of (a) as-prepared and calcined at (b) $250{ }^{\circ} \mathrm{C}$, (c) $350{ }^{\circ} \mathrm{C}$ and (d) $500{ }^{\circ} \mathrm{C} \mathrm{TiO}_{2}$ nanofibers.

from $412 \mathrm{~nm} \pm 104 \mathrm{~nm}$ of the as-prepared (Fig. 2a) to $80.8 \mathrm{~nm} \pm$ $44.5 \mathrm{~nm}$ of the $500{ }^{\circ} \mathrm{C}$ calcined samples (Fig. 2f). The largest reduction in fiber diameters from 210 to $128 \mathrm{~nm}$ was observed with increasing temperature from 300 to $350{ }^{\circ} \mathrm{C}$. Detailed analysis from 350 to $500{ }^{\circ} \mathrm{C}$ revealed that roughening and restructuring of the fiber surface occurs for $T_{\mathrm{s}} \geq 400{ }^{\circ} \mathrm{C}$. This was in-line with the granular morphology observed by TEM (Fig. 1d, inset) and is attributed to the nucleation of $\mathrm{TiO}_{2}$ crystals on the nanofiber surfaces (Fig. 2d).

Although the visible TEM and SEM fiber diameter decreased monotonously with increasing calcination temperature, the available surface for water adsorption was maximal below 500 ${ }^{\circ} \mathrm{C}$. Fig. 4a shows the specific surface area (SSA) of the fibers (Fig. 4a, triangles) as a function of the calcination temperature.

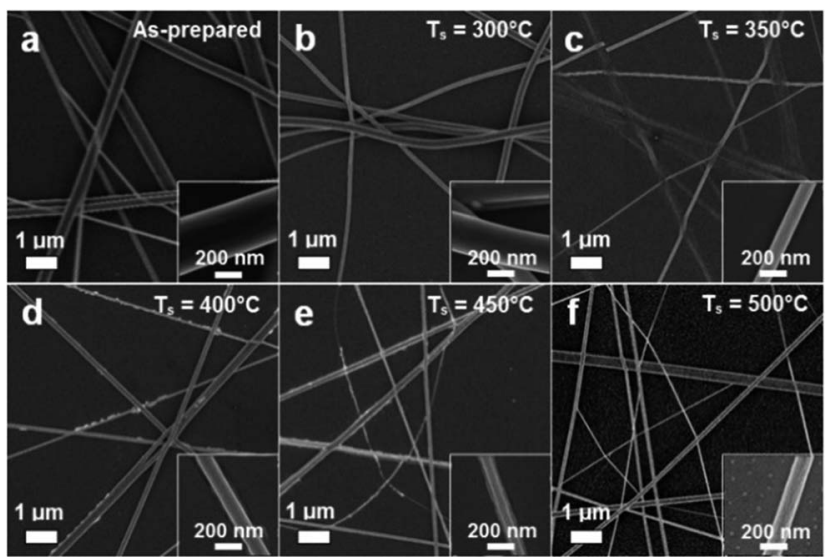

Fig. 2 SEM images of (a) as-prepared and calcined fibers at (b) $300^{\circ} \mathrm{C}$, (c) $350^{\circ} \mathrm{C}$, (d) $400^{\circ} \mathrm{C}$, (e) $450^{\circ} \mathrm{C}$ and (f) $500^{\circ} \mathrm{C}$.
The SSA increased drastically from ca. 65 to $106 \mathrm{~m}^{2} \mathrm{~g}^{-1}$ with increasing $T_{\mathrm{s}}$ from 300 to $350{ }^{\circ} \mathrm{C}$. This is only partially justified by the fiber diameter reduction observed by SEM and TEM (Fig. 2b and c). This surface restructuring is attributed to the desorption of (PVP) polymer residuals.

The XRD spectra of the calcined samples (Fig. 3) provided further understanding of the observed surface restructuring (Fig. 1 and 2). Up to a calcination temperature of $350{ }^{\circ} \mathrm{C}$, the $\mathrm{TiO}_{2}$ nanofibers were amorphous with no visible diffraction peaks (Fig. 3). At $T_{\mathrm{s}}$ of $400{ }^{\circ} \mathrm{C}$, anatase crystals with an average size of $8.8 \mathrm{~nm}$ were nucleated. Further increasing $T_{\mathrm{s}}\left(450{ }^{\circ} \mathrm{C}\right)$ increased the crystal size to $12.0 \mathrm{~nm}$ preserving the pure anatase structure. At $500{ }^{\circ} \mathrm{C}$, the formation of a small amount $(8.2 \mathrm{wt} \%)$ of rutile was observed and the anatase $d_{\mathrm{XRD}}$ reached $17.4 \mathrm{~nm}$. This is in line with the TEM morphology observed at $500{ }^{\circ} \mathrm{C}$ and suggests that the multi-granular texture of the fibers is caused by the formation of large anatase crystals.

Increasing the calcination temperature step-wise to $500{ }^{\circ} \mathrm{C}$ resulted in a $50 \%$ SSA reduction. This was characterized by an initial SSA drop to $42 \pm 5 \mathrm{~m}^{2} \mathrm{~g}^{-1}$ at $450{ }^{\circ} \mathrm{C}$ and thereafter its leveling-off up to $500{ }^{\circ} \mathrm{C}$. Considering that the fiber diameter of the $350^{\circ} \mathrm{C}$ calcined samples was slightly larger than that of the $500{ }^{\circ} \mathrm{C}$ ones, the higher SSA of amorphous $\mathrm{TiO}_{2}$ nanofibers indicates the formation of a mesoporous surface morphology. This is further supported by the large pore volume and small $(4.7 \mathrm{~nm})$ average pore size measured upon partial removal of the organic scaffold at $350{ }^{\circ} \mathrm{C}$ (Table 1 ).

At a higher magnification (Fig. 1c, inset) the smoothappearing fibers calcined at $350{ }^{\circ} \mathrm{C}$ had a more discrete structure, suggesting the presence of nano-scale pores. The high SSA achieved here by these amorphous nanostructures $\left(T_{\mathrm{s}}=350{ }^{\circ} \mathrm{C}\right)$ is comparable to the highest reported for $\mathrm{TiO}_{2}$ nanofibers ${ }^{26,37,38}$ and is, to the best of our knowledge, also the highest ever achieved with the PVP-TTIP system. The hierarchical morphology of these amorphous fiber coatings combines the

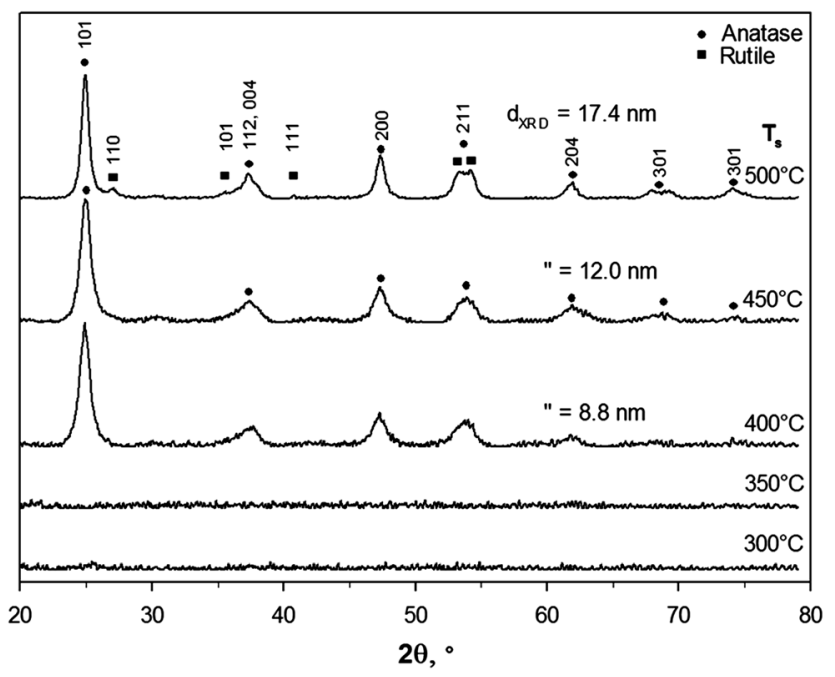

Fig. 3 XRD spectra of the calcined fibers and corresponding anatase and rutile phase peaks. The average crystal size was $8.8,12.0$ and 17.4 $\mathrm{nm}$ for the 400,450 and $500{ }^{\circ} \mathrm{C}$ samples. 
Table 1 Properties and performance of the $\mathrm{TiO}_{2}$ fibers, and comparison with selected literature data ${ }^{a}$

\begin{tabular}{|c|c|c|c|c|c|c|}
\hline Morphology & $\mathrm{d}_{\mathrm{EM}} \mathrm{nm}$ & SSA $\mathrm{m}^{2} \mathrm{~g}^{-1}$ & $\mathrm{PV} \mathrm{cm}^{3} \mathrm{~g}^{-1}$ & $\mathrm{CA}_{\mathrm{i}}^{\circ}$ & $\mathrm{CA}_{\mathrm{d}}{ }^{\circ}$ & Ref. \\
\hline Amorphous $\mathrm{TiO}_{2}$ fibers $T_{\mathrm{s}}=350{ }^{\circ} \mathrm{C}$ & 128 & 105.8 & 0.100 & 8.5 & 9.2 & This work \\
\hline $92 \mathrm{wt} \%$ Anatase fibers $T_{\mathrm{s}}=500{ }^{\circ} \mathrm{C}$ & 81 & 44.8 & 0.076 & 0.0 & 7.0 & This work \\
\hline ED amorphous NPs & - & - & - & 12 & 39 & 27 \\
\hline FSP NPs & - & - & - & $5-8$ & 10 & 15 \\
\hline
\end{tabular}

${ }^{a} d_{\mathrm{EM}}$ - fiber diameter determined by electron microscopy. PV - pore volume of fibers. $\mathrm{CA}_{\mathrm{i}}-$ initial contact angle upon synthesis. CA $\mathrm{d}-$ contact angle after incubation in darkness for $>12$ hours. ED - Electrodeposited. FSP - Flame spray pyrolysis. ES - Electrospun. NPs - Nanoparticles.

macro-scale porosity of the fiber layers (Fig. 2c) with the nanoscale roughness of their mesoporous surface (Fig. 4a and b) offering an optimal structure for the rapid penetration and spreading of water.

\section{Optical and wetting performance}

The optical performance of the nanofiber coatings was investigated as a function of the calcination temperature. Fig. 5 shows the transmittance at an incoming light wavelength of $400 \mathrm{~nm}$ (circles) and $600 \mathrm{~nm}$ (triangles) from the as-prepared to the
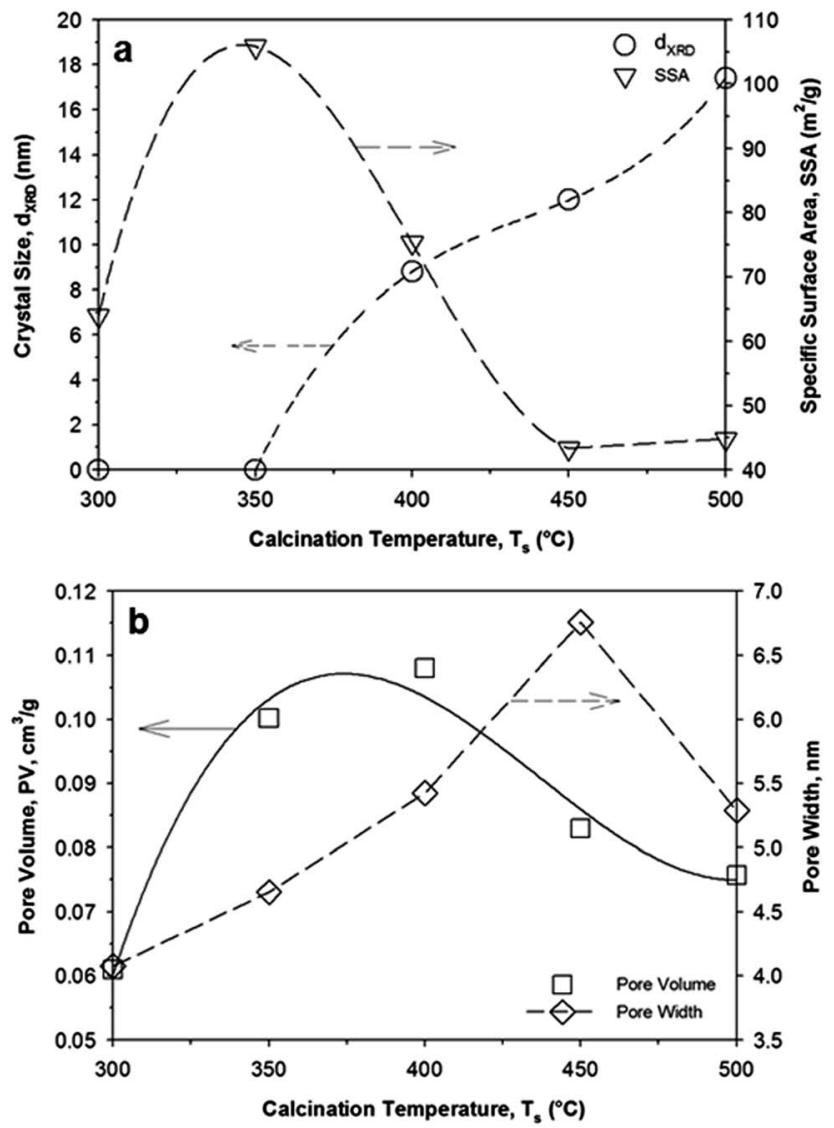

Fig. 4 (a) Average crystal size ( $d_{\mathrm{XRD}}$, circles) and specific surface area (SSA, triangles) as a function of the calcination temperature $\left(T_{s}\right)$. (b) Pore volume (PV, squares) and pore width (PW, diamonds) as a function of calcination temperature $\left(T_{s}\right)$.
$500{ }^{\circ} \mathrm{C}$ calcined samples. The as-prepared coatings' transmittance was $c a .77 .5 \%$ for both wavelengths. This was attributed to the presence of PVP and large fiber diameters ( $c a$. $440 \mathrm{~nm}$ ), leading to strong light scattering and absorption. Calcining the samples to $250{ }^{\circ} \mathrm{C}$ increased transmittance by $c a$. $10 \%$, in line with the suggested partial decomposition and desorption of the PVP matrix.

Increasing $T_{\mathrm{s}}$ to $350{ }^{\circ} \mathrm{C}$ gradually increased the transmittance up to $c a .92 .5 \%$ and thus $c a .2 .5 \%$ below that of the bare glass slides. Further increments in $T_{\mathrm{s}}$ (up to $500^{\circ} \mathrm{C}$ ) did not enhance light transmittance. This is in line with the stabilization of the fiber diameter observed by SEM and TEM (Fig. 1 and 2) and the relatively small amount of organic residuals detected by FTIR at $350{ }^{\circ} \mathrm{C}$ (Fig. 8). Transmittance values between $85 \%{ }^{24}$ to $90 \%{ }^{23}$ are considered sufficient for most optical applications. The optical performance obtained here is comparable to state-of-the-art coatingss, ${ }^{23,24}$ showcasing the suitability of these amorphous nanofibers for applications in micro-lenses, solar cells and photo-detectors.

The long-term coating wetting properties were quantified as a function of the calcination temperature by measurement of the dynamic contact angle with a water droplet upon keeping the samples in the dark for $72 \mathrm{~h}\left(\mathrm{CA}_{\mathrm{d}}\right)$. Fig. 6 compares the

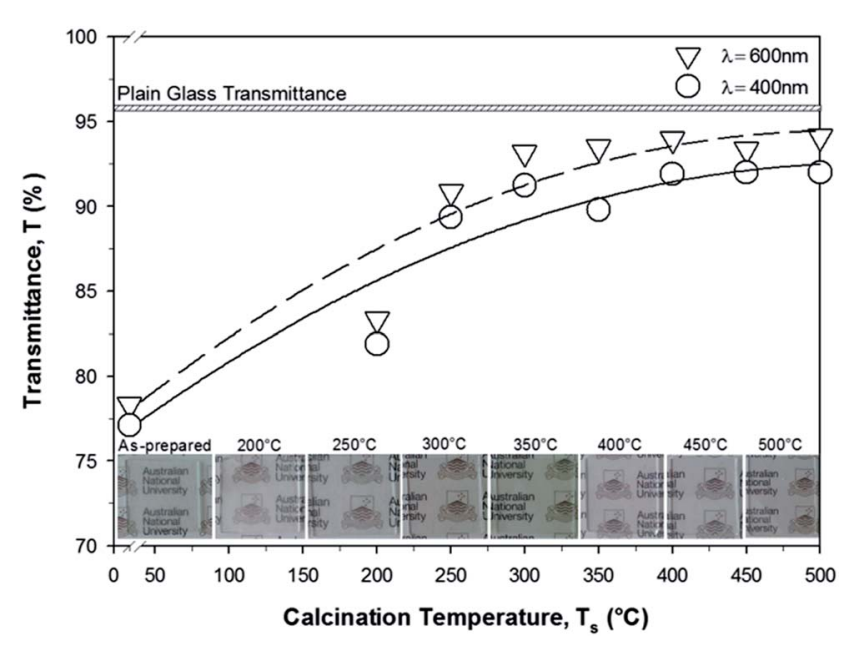

Fig. 5 Light transmittance through the coatings at a wavelength of $400 \mathrm{~nm}$ (circles) and $600 \mathrm{~nm}$ (triangles) as a function of the calcination temperature. 


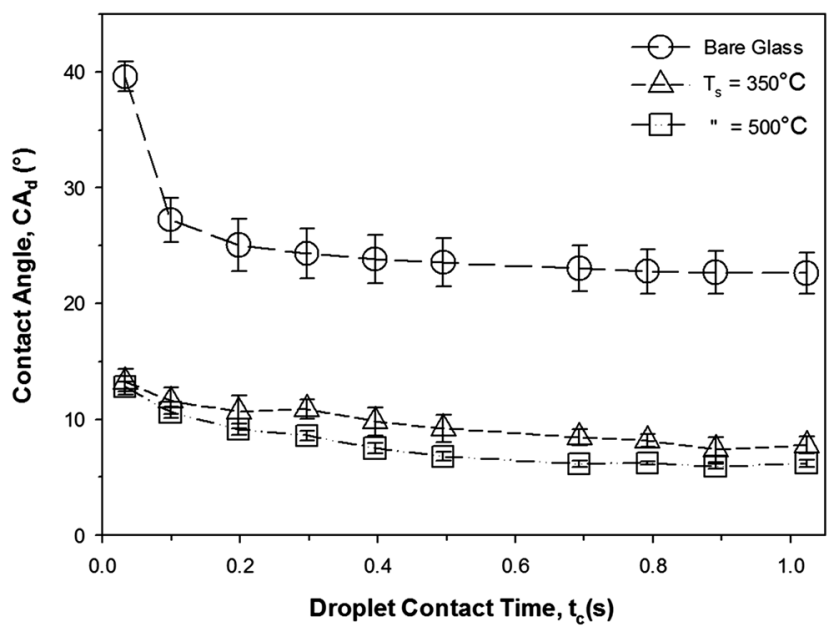

Fig. 6 Dynamic water contact angle of bare (circles) and $\mathrm{TiO}_{2}$ nanofibers coated glasses calcined at (triangles) $350{ }^{\circ} \mathrm{C}$ and (squares) $500{ }^{\circ} \mathrm{C}$ after 72 hours in the darkness.

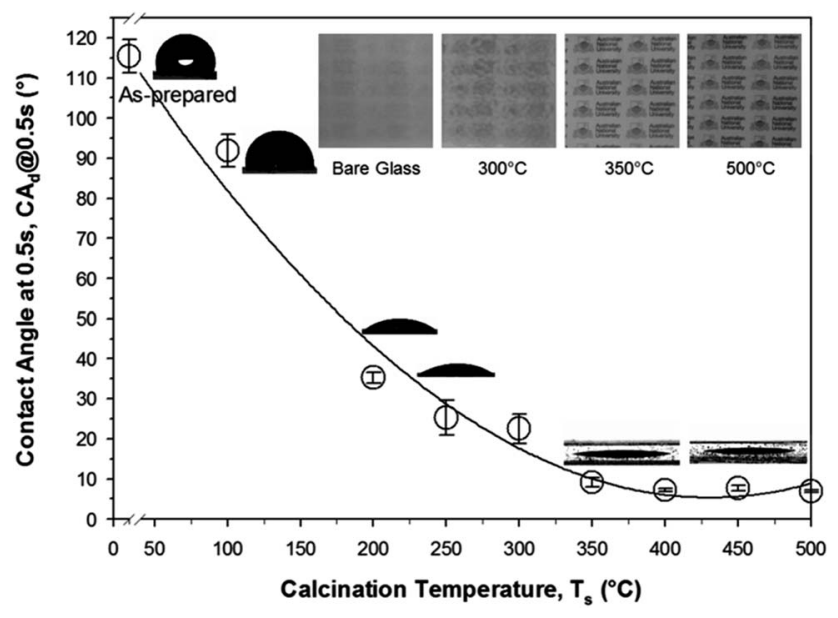

Fig. 7 Dynamic water contact angle and (insets) optical images of water droplets as a function of the calcination temperature. Optical images (top right insets) of bare and coated glass in a water vapor stream.

dynamic water contact angle for the $350{ }^{\circ} \mathrm{C}$ (triangles) and $500{ }^{\circ} \mathrm{C}$ (square) calcined coatings with bare glass (circles).

Upon a contact time of $0.5 \mathrm{~s}$, the $\mathrm{CA}_{\mathrm{d}}$ of the bare glass converged toward $c a .25^{\circ}$. In contrast, the glass with the $350{ }^{\circ} \mathrm{C}$ and $500{ }^{\circ} \mathrm{C}$ coatings reached a $\mathrm{CA}_{\mathrm{d}}$ of $c a .8 .1 \pm 1^{\circ}\left(t_{\mathrm{c}}=0.5 \mathrm{~s}\right)$. Although the latter had a slightly lower $\mathrm{CA}_{\mathrm{d}}$ (Table 1), these effects were minimal, and the actual performance was almost indistinguishable with both coatings satisfying super-hydrophilic requirements. This is attributed to the larger SSA and pore volume of the amorphous fibers (Table 1) compensating for the higher $\mathrm{H}_{2} \mathrm{O}$ affinity of the anatase surface. It is worth noticing that the initial contact angle at $0.5 \mathrm{~s}\left(\mathrm{CA}_{\mathrm{i}}\right)$ of the $500{ }^{\circ} \mathrm{C}$ samples (Table 1 ) was $0^{\circ}$ indicating a partial deactivation of the anatase surface upon $72 \mathrm{~h}$ in darkness. In contrast, for the amorphous fibers the initial $\left(8.5^{\circ}\right)$ and post-light deprivation
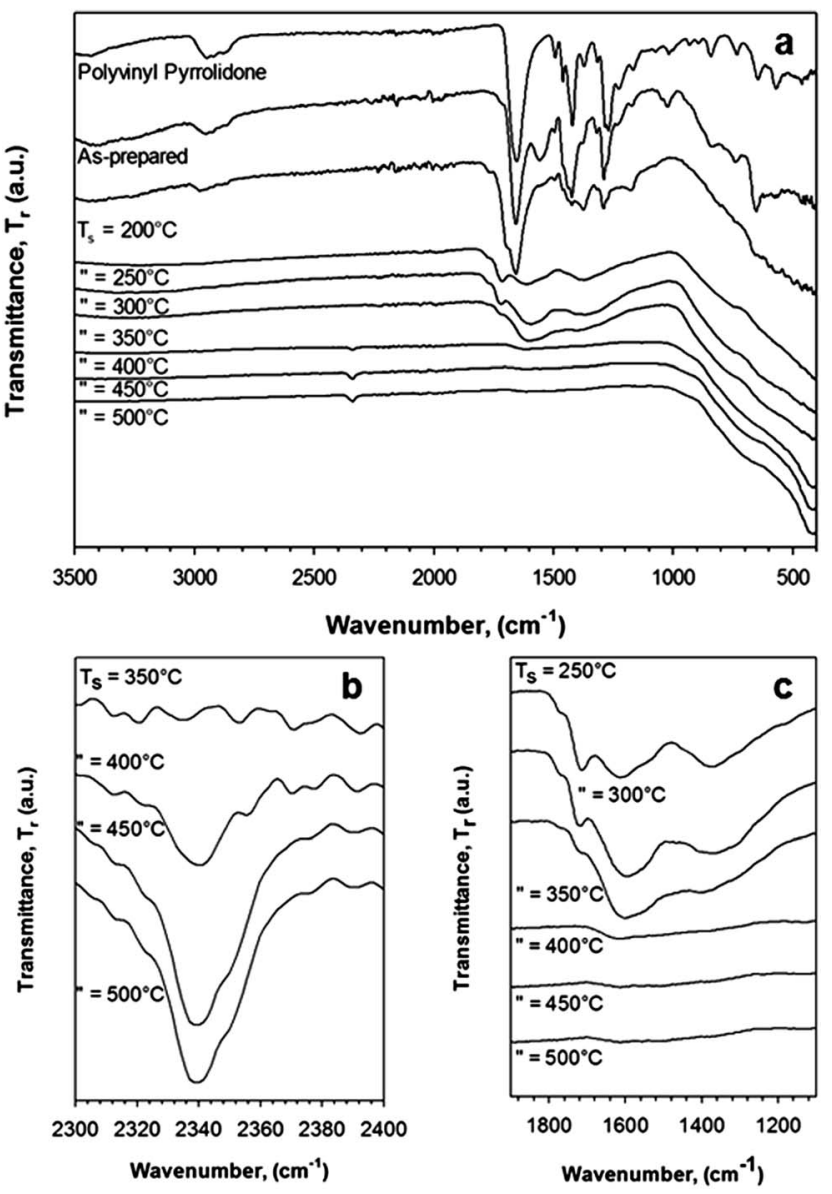

Fig. 8 FTIR spectra (a) of electrospun $\mathrm{TiO}_{2}$ nanofibers as a function of the calcination temperature $\left(T_{\mathrm{s}}\right)$. Magnifications of the FTIR spectra from (b) from $2300 \mathrm{~cm}^{-1}$ to $2400 \mathrm{~cm}^{-1}$ depicting atmospheric $\mathrm{CO}_{2}$ adsorption, and (c) from $1100 \mathrm{~cm}^{-1}$ to $1900 \mathrm{~cm}^{-1}$ depicting the loss of organics between $250-400{ }^{\circ} \mathrm{C}$.

$\left(9.2^{\circ}\right)$ contact angles (Table 1 ) were nearly identical suggesting inherent super-hydrophilicity.

Fig. 7 shows the initial dynamic water contact angle at $0.5 \mathrm{~s}$ as a function of the calcination temperature. The as-prepared coatings (Fig. 7) were hydrophobic with a CA of $115^{\circ}$. The $\mathrm{CA}_{\mathrm{d}}$ decreased sharply with increasing calcination temperature with an asymptotic behavior. The largest CA drop occurred from 100 to $250{ }^{\circ} \mathrm{C}\left(\mathrm{CA}_{\mathrm{d} \_250}{ }^{\circ} \mathrm{C}=25^{\circ}\right)$. Further increasing $T_{\mathrm{s}}$ to $350{ }^{\circ} \mathrm{C}$ led to a $\mathrm{CA}_{\mathrm{d}}$ of below $10^{\circ}$ and thus to the attainment of superhydrophilicity $\left(\mathrm{CA}_{\mathrm{d} \_350}{ }^{\circ} \mathrm{C}=9 \cdot 2^{\circ}\right)$. Small reductions $\left(\approx 1^{\circ}\right)$ in CA were obtained for $T_{\mathrm{s}} \geq 400{ }^{\circ} \mathrm{C}$. To assess the durability of the films, subsequent multi-drop tests were conducted on the 350 ${ }^{\circ} \mathrm{C}$ and $500{ }^{\circ} \mathrm{C}$ calcined films. No variation of the water contact angle and macroscopic film structure was observed up to 6 hours wetting-drying cycles.

The coating anti-fogging performance was assessed by placing the bare and coated glass slides in a water vapor stream. Uncoated glass fogged within a few seconds due to the condensation of water droplets (Fig. 7, insets). The coating calcined at $300{ }^{\circ} \mathrm{C}$ demonstrated reduced fogging and improved transmittance. However, the background visibility was still 
severely hindered by partial fogging. The coatings calcined at $T_{\mathrm{s}}$ $\geq 350{ }^{\circ} \mathrm{C}$ demonstrated excellent anti-fogging performance with a clear and transparent appearance during the entire period of vapor exposure. This indicates that both a mesoporous surface and removal of most organics are required to obtain superhydrophilicity. These results show, for the first time, that lowtemperature synthesized amorphous $\mathrm{TiO}_{2}$, not requiring UVactivation, can achieve comparable wetting performance as crystalline anatase assembled at high-temperatures.

\section{Nanofiber surface analysis}

To explain the strong variation in wetting and anti-fogging performance observed from 300 to $350{ }^{\circ} \mathrm{C}$, the fiber surface composition was investigated by FTIR. The onset of PVP scaffold decomposition was found to take place between 250$350{ }^{\circ} \mathrm{C}$, in line with previous reports ${ }^{\mathbf{3 9 , 4 0}}$ where diminishing organic peaks ${ }^{41}$ such as $\mathrm{C}=\mathrm{O}$ stretch at $1650 \mathrm{~cm}^{-1}, \mathrm{CH}_{2}$ scissor at $1419 \mathrm{~cm}^{-1}, \mathrm{CH}_{2}$ twist, wag and $\mathrm{C}-\mathrm{N}$ stretch at $1200-1300$ $\mathrm{cm}^{-1}$ occurred. The Ti-O bonds were found to become predominant at a calcination temperature of $250{ }^{\circ} \mathrm{C}$ as indicated by strong inorganic Ti-O peaks ${ }^{42}$ between $450-550 \mathrm{~cm}^{-1}$. This explains the strong drop in contact angle $\left(\Delta \mathrm{CA}=90^{\circ}\right)$ observed for calcination temperatures above $200{ }^{\circ} \mathrm{C}$ (Fig. 7).

Further increasing the calcination temperature led to a reduction of organic related peaks that completely disappeared only at $400{ }^{\circ} \mathrm{C}$. These findings further indicate that the fiber diameter shrinkage dynamics is controlled by the decomposition and desorption of the polymer precursor (Fig. 1 and 2). The remaining organic peaks $\left(\sim 1650 \mathrm{~cm}^{-1}\right)$ at $350{ }^{\circ} \mathrm{C}$ were mostly attributed to distorted $\mathrm{C}=\mathrm{O}$, and appeared to have a minimal impact on the surface water affinity (Fig. 7). A peak at $2340 \mathrm{~cm}^{-1}$ was also found for $T_{\mathrm{s}} \geq 400{ }^{\circ} \mathrm{C}$, suggesting the presence of physisorbed carbon dioxide $\left(\mathrm{CO}_{2}\right)$. This is in line with previous reports indicating considerable adsorption of atmospheric $\mathrm{CO}_{2}$ on crystalline $\mathrm{TiO}_{2}$. It is worth noting that, even after an extended incubation period of 8 days, the amorphous $\mathrm{TiO}_{2}\left(T_{\mathrm{S}}=\right.$ $350{ }^{\circ} \mathrm{C}$ ) did not develop this $\mathrm{CO}_{2}$ peak (not shown). This is in line with the TGA analysis of the fiber mats (Fig. S1 $\dagger$ ) showing that most of the organics are desorbed between 300 and $400{ }^{\circ} \mathrm{C}$. Furthermore, analysis of the organics desorption dynamics at isothermal conditions (Fig. S2 $\dagger$ ) suggests that the critical transitional temperature for organics removal and achievement of super-hydrophilicity is close to $350{ }^{\circ} \mathrm{C}$.

\section{Conclusions}

An optimal $\mathrm{TiO}_{2}$ nanofiber morphology was determined for fabrication of flexible, non-UV augmented super-hydrophilic coatings having superior transparency and anti-fogging performance. For the first time, it is shown that very-high SSA (>100 $\mathrm{m}^{2} \mathrm{~g}^{-1}$ ), hierarchical, amorphous $\mathrm{TiO}_{2}$ nanofibers, not requiring UV activation, have comparable inherent wetting performance to crystalline anatase. These amorphous fiber coatings were synthesized by rapid $(1 \mathrm{~min})$ electrospinning leading to enhanced and prolonged (72 $\mathrm{h}$ in the darkness) super-hydrophilicity. It was found that amorphous Ti-O bonds become predominant at $250{ }^{\circ} \mathrm{C}$ leading to a considerable reduction $\left(\Delta \mathrm{CA}=90^{\circ}\right)$ of the water contact angle. Calcination at $350{ }^{\circ} \mathrm{C}$ was required to remove most residual organics and obtain quasi-perfect wetting $\left(\mathrm{CA}_{\mathrm{d}}\right.$ at $\left.0.5 \mathrm{~s}<10^{\circ}\right)$. These lowtemperature synthesized amorphous nanofibers have potential for development of super-hydrophilic coatings with numerous applications such as anti-fog glass, microfluidic devices and water filtration membranes.

\section{Acknowledgements}

We thank Prof. Vincent Craig, Prof. Tim Senden (RSPE, ANU), Dr. Adrian Lowe (RSE, ANU) and Prof. Takuya Tsuzuki (RSE, ANU) for their valuable advice and the use of their laboratories. WSYW acknowledges the PhD research fellowship from the Australian National University. ALR was supported by an Australian Postgraduate Award; DRN was supported by an Australian Research Council Australian Postdoctoral Fellowship, and subsequently by a NHMRC Career Development Fellowship. AT was supported by a Future Engineering Research Leadership (FERL) fellowship. This work was partially supported by the ANU-Discovery Translation Fund grant (DTF078).

\section{Notes and references}

1 R. Wang, K. Hashimoto, A. Fujishima, M. Chikuni, E. Kojima, A. Kitamura, M. Shimohigoshi and T. Watanabe, Nature, 1997, 388, 431-432.

2 D. Glö $\beta$, P. Frach, O. Zywitzki, T. Modes, S. Klinkenberg and C. Gottfried, Surf. Coat. Technol., 2005, 200, 967-971.

3 M. Machida, K. Norimoto, T. Watanabe, K. Hashimoto and A. Fujishima, J. Mater. Sci., 1999, 34, 2569-2574.

4 F. Ç. Cebeci, Z. Wu, L. Zhai, R. E. Cohen and M. F. Rubner, Langmuir, 2006, 22, 2856-2862.

5 D. Tahk, T.-i. Kim, H. Yoon, M. Choi, K. Shin and K. Y. Suh, Langmuir, 2010, 26, 2240-2243.

6 P. Patel, C. K. Choi and D. D. Meng, JALA, 2010, 15, 114-119.

7 R. Blossey, Nat. Mater., 2003, 2, 301-306.

8 M. L. Carman, T. G. Estes, A. W. Feinberg, J. F. Schumacher, W. Wilkerson, L. H. Wilson, M. E. Callow, J. A. Callow and A. B. Brennan, Biofouling, 2006, 22, 11-21.

9 H. Thissen, T. Gengenbach, R. du Toit, D. F. Sweeney, P. Kingshott, H. J. Griesser and L. Meagher, Biomaterials, 2010, 31, 5510-5519.

10 B. H. W. Hendriks, S. Kuiper, M. A. J. As, C. A. Renders and T. W. Tukker, Opt. Rev., 2005, 12, 255-259.

11 S. Shahi, Nat. Photonics, 2010, 4, 350.

12 E. Ueda and P. A. Levkin, Adv. Mater., 2013, 25, 1234-1247.

13 R. P. Garrod, L. G. Harris, W. C. E. Schofield, J. McGettrick, L. J. Ward, D. O. H. Teare and J. P. S. Badyal, Langmuir, 2006, 23, 689-693.

14 C. Li, Z. Wang, P. I. Wang, Y. Peles, N. Koratkar and G. P. Peterson, Small, 2008, 4, 1084-1088.

15 A. Tricoli, M. Righettoni and S. E. Pratsinis, Langmuir, 2009, 25, 12578-12584.

16 M. Harju, E. Levänen and T. Mäntylä, Appl. Surf. Sci., 2006, 252, 8514-8520. 
17 M. M. Gentleman and J. A. Ruud, Langmuir, 2009, 26, 14081411.

18 S. Wu, Polymer Interface and Adhesion, Taylor \& Francis, 1982. 19 A. Mills and M. Crow, Int. J. Photoenergy, 2008, 2008, 1-6.

20 A. Kanta, R. Sedev and J. Ralston, Langmuir, 2005, 21, 24002407.

21 J. Drelich and E. Chibowski, Langmuir, 2010, 26, 1862118623.

22 Q. Li, D. Sun and H. Kim, Mater. Res. Bull., 2011, 46, 20942099.

23 V. A. Ganesh, A. S. Nair, H. K. Raut, T. M. Walsh and S. Ramakrishna, RSC Adv., 2012, 2, 2067.

24 F. Li, Q. Li and H. Kim, Appl. Surf. Sci., 2013, 276, 390-396.

25 A. Kumar, R. Jose, K. Fujihara, J. Wang and S. Ramakrishna, Chem. Mater., 2007, 19, 6536-6542.

26 I.-D. Kim, A. Rothschild, B. H. Lee, D. Y. Kim, S. M. Jo and H. L. Tuller, Nano Lett., 2006, 6, 2009-2013.

27 S. Karuppuchamy and J. M. Jeong, Mater. Chem. Phys., 2005, 93, 251-254.

28 Y. Gao, Y. Masuda and K. Koumoto, Langmuir, 2004, 20, 3188-3194.

29 K. Guan, Surf. Coat. Technol., 2005, 191, 155-160.

30 A. Eshaghi and A. Eshaghi, Bull. Mater. Sci., 2012, 35, 137142.
31 A. S. Zuruzi, Y. H. Yeo, A. J. Monkowski, C. S. Ding and N. C. MacDonald, Nanotechnology, 2013, 24, 245304.

32 H. Y. Lee, Y. H. Park and K. H. Ko, Langmuir, 2000, 16, 72897293.

33 J.-M. Wu, H. C. Shih and W.-T. Wu, Chem. Phys. Lett., 2005, 413, 490-494.

34 A. Tricoli, M. Graf, F. Mayer, S. Kuühne, A. Hierlemann and S. E. Pratsinis, Adv. Mater., 2008, 20, 3005-3010.

35 D. Li and Y. Xia, Nano Lett., 2003, 3, 555-560.

36 S. H. Hwang, C. Kim, H. Song, S. Son and J. Jang, ACS Appl. Mater. Interfaces, 2012, 4, 5287-5292.

37 W. Zhang, R. Zhu, L. Ke, X. Liu, B. Liu and S. Ramakrishna, Small, 2010, 6, 2176-2182.

38 P. S. Kumar, S. A. S. Nizar, J. Sundaramurthy, P. Ragupathy, V. Thavasi, S. G. Mhaisalkar and S. Ramakrishna, J. Mater. Chem., 2011, 21, 9784.

39 D. Dollimore and G. R. Heal, Carbon, 1967, 5, 65-72.

40 M. I. Loría-Bastarrachea, W. Herrera-Kao, J. V. CauichRodríguez, J. M. Cervantes-Uc, H. Vázquez-Torres and A. Ávila-Ortega, J. Therm. Anal. Calorim., 2010, 104, 737-742. 41 Y. Borodko, S. E. Habas, M. Koebel, P. Yang, H. Frei and G. A. Somorjai, J. Phys. Chem. B, 2006, 110, 23052-23059.

42 N. B. Colthup, L. H. Daly and S. E. Wiberley, Introduction to infrared and Raman spectroscopy, Academic Press, 1990. 